\title{
Perfil fitoquímico, susceptibilidade antibacteriana e capacidade antioxidante das folhas de Croton urucurana Baillon (Euphorbiaceae)
}

\author{
Phytochemical profile, antibacterial susceptibility and antioxidant \\ capacity of leaves from Croton urucurana Baillon (Euphorbiaceae)
}

Recebido em: 23/04/2017

Aceito em: $\quad 17 / 07 / 2017$
Sarah Caroline de Souza SILVA ${ }^{1}$; Mônica Alcântara ALVES ${ }^{2}$; Sabrina Araujo de SOUSA²; José Ribamar de Souza NOGUEIRA ${ }^{3}$; Diegue Henrique Nascimento MARTINS ${ }^{1}$; Yris Maria FONSECA-BAZZO ${ }^{1}$; Alvaro Carlos GALDOS-RIVEROS ${ }^{4}$ ${ }^{1}$ Departamento de Farmácia (FAR), Faculdade de Ciências da Saúde, Universidade de Brasília. Asa Norte, CEP: 70910-900. Brasília, DF, Brasil. ${ }^{2}$ Faculdade de Farmácia de Brasília, Anhanguera Institucional Ltda. QS 1, rua 212, lotes 11,13 e 15, Águas Claras, CEP 71950-550. Taguatinga, DF, Brasil. ${ }^{3}$ Universidade Católica de Brasília. Campus I, QS 07, Lote 01, EPCT, Águas Claras, CEP 71966-700. Taguatinga, DF, Brasil. ${ }^{4}$ Instituto

de Ciências da Saúde, Universidade Federal de Mato Grosso, Campus Universitário de Sinop. Avenida Alexandre Ferronato, 1.200, Setor Industrial, CEP: 78.557-267.

Sinop, MT, Brasil.E-mail: alvarogaldos@usp.br

\section{ABSTRACT}

Croton urucurana Baillon, popularly known as "sangria d'água", belongs to the Euphorbiaceae family. The species has a great importance in folk medicine as antibacterial, anti-inflammatory, antiseptic, antiviral, antidiarrheal, intestinal antisecretory and cicatrizant remedies. The objective of this study was to verify the presence, in the aqueous, ethanolic and hydroalcoholic extracts, of secondary metabolites (alkaloids, anthraquinones, steroids/triterpenoids, flavonoids, glycosides, saponins and tannins), analyze the inhibition of bacteria Staphylococcus aureus ATCC 25923 and Salmonella thyphimurium ATCC 14028 growth, and evaluate the antioxidant activity by the DPPH method. Considering the phytochemical profile, the best extract was the aqueous; the bacteria susceptibility was inhibited with the ethanolic extract; and the extract with the highest antioxidant activity was the hydroalcoholic, presenting $\mathrm{IC}_{50} 1.3 \mu \mathrm{g} /$ $\mathrm{mL}$. It was concluded that the extracts of Croton urucurana Baillon show interesting results and that further investigations must be carried out for the better elucidation of its benefits.

Keywords: Croton urucurana Baillon; phytochemical; antioxidant; antibacterial; extract.

\section{RESUMO}

Croton urucurana Baillon, espécie conhecida popularmente como "sangria d'água", pertence à família Euphorbiaceae, possui grande importância na medicina popular, a qual lhe atribui propriedades antibacterianas, anti-inflamatórias, antissépticas, antivirais, antidiarreicas, antissecretória intestinal e cicatrizante. Os objetivos deste estudo foram verificar a presença, nos extratos aquoso, etanólico e hidroalcoólico, de metabolitos secundários (alcaloides, antraquinonas, esteroides/triterpenoides, flavonoides, glicosídeos, saponinas e taninos), analisar a inibição do crescimento das bactérias Staphylococcus aureus ATCC 25923 e Salmonella thyphimurium ATCC 14028, e verificar a atividade antioxidante através do método DPPH. Para o perfil fitoquímico o melhor extrato foi o aquoso, quanto à susceptibilidade bacteriana, houve inibição com o extrato etanólico e o extrato com a maior atividade antioxidante foi o hidroalcóolico, apresentando $\mathrm{IC}_{50} 1,3 \mu \mathrm{g} / \mathrm{mL}$. Considerando os resultados obtidos no estudo, foi possível concluir que os extratos da Croton urucurana Baillon apresentam resultados interessantes e que mais investigações devem ser realizadas para a elucidação aprimorada dos seus benefícios.

Palavras-chave: Croton urucurana Baillon; fitoquímica; antioxidante; antimicrobiana; extrato. 


\section{INTRODUÇÃO}

O Cerrado ocupa cerca de $24 \%$ do Brasil e é o segundo maior bioma do território nacional (1). Várias espécies reconhecidas como alimentícias, madeireiras, frutíferas, artesanais e medicinais (2) se destacam, tais como Morus alba (3), Cecropia pachystachya (4), Plantago major (5) e Euphorbia tirucalli (6), as quais apresentam diversas propriedades terapêuticas.

Euphorbiaceae está entre uma das maiores famílias botânicas, complexas e diversas de Angiospermas. Ela é composta por 334 gêneros e mais de 8.000 espécies, que são distribuídos principalmente nos trópicos nos mais variados tipos de vegetação e habitats. Apresenta grande destaque na atividade econômica, através da alimentação humana e na medicina a partir do conhecimento popular $(7,8)$.

O gênero Croton compreende pelo menos 800 espécies dos trópicos (9). Croton urucurana Baillon é difundido em áreas úmidas e ribeirinhas e é comumente encontrado no Sul do Brasil, Norte da Argentina, Paraguai e Uruguai (10). A espécie é conhecida popularmente em Estados brasileiros como sangria d'água, adraga, adrago, adrago-branco, urucurana, pau-de-sangue e coração-de-cristo; possui grande importância na medicina popular, a qual the atribui propriedades antibacterianas, anti-inflamatórias, antissépticas, antivirais, antidiarreicas, antissecretória intestinal, cicatrizantes, antioxidante e antirreumáticas (11-14).

O mau uso de antibióticos na medicina, na produção de alimentos para animais e na agricultura, está tornando bactérias resistentes aos antibióticos, de difícil ou impossível tratamento. Além disso, estão se tornando cada vez mais comuns e causando uma crise global de saúde $(15,16)$.

A busca por alternativas terapêuticas que minimizem o impacto da resistência desenvolvida pelos microrganismos frente aos fármacos, motiva a avaliação da possível atividade antimicrobiana de plantas medicinais e fitoterápicos (17). Extratos e óleos essenciais de plantas mostraram-se eficientes no controle do crescimento de uma ampla variedade de microrganismos, incluindo fungos filamentosos, leveduras e bactérias. Usos práticos dessas atividades são sugeridos em humanos e animais, bem como na indústria de alimentos (16).

Apesar dos grandes avanços observados na medicina moderna, as plantas medicinais ainda desempenham importante papel na saúde mundial (18). Existem obstá- culos na utilização de medicamentos pela população de diferentes países em desenvolvimento, que vão desde o acesso aos hospitais até o difícil acesso ao tratamento. $\mathrm{O}$ fácil acesso às plantas medicinais influencia a sua utilização pela população carente (19). Os investimentos em pesquisas para a produção de medicamentos, a partir da flora brasileira, contribuem para o acesso da população e o seu uso racional (20).

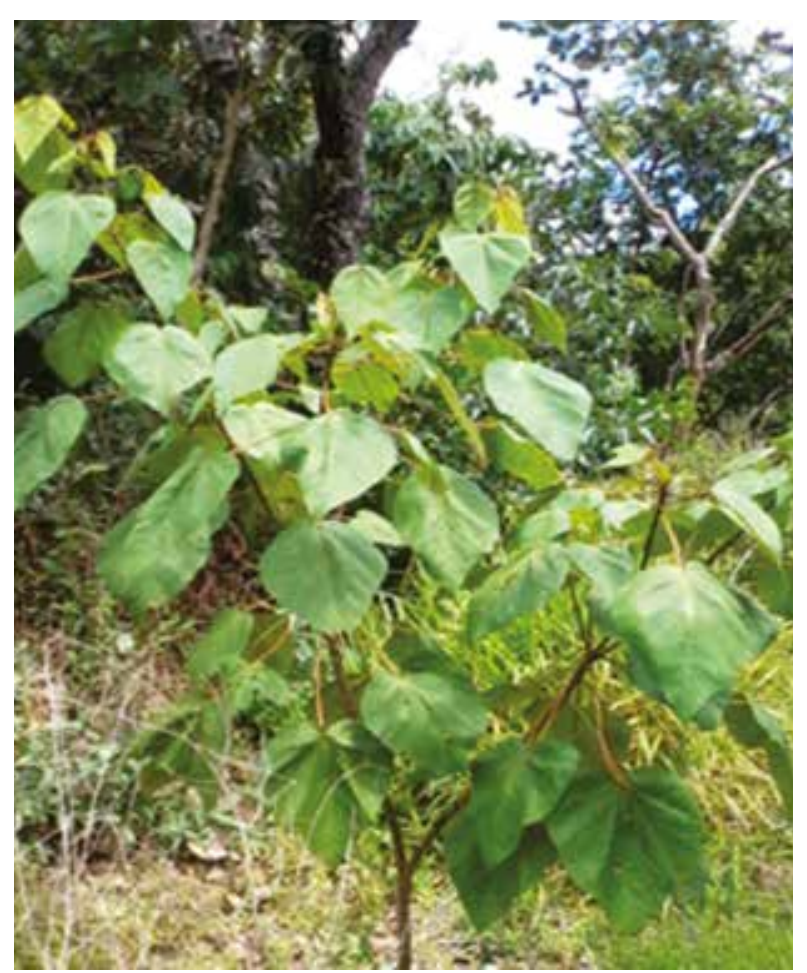

Figura 1. Arbusto da Sangra d'agua, Croton urucurana Baillon.

\section{MÉTODOS}

Para a realização do presente trabalho, foram utilizadas técnicas de análise fitoquímica adaptado de Silv e cols. (2010) (21). E a susceptibilidade bacteriana foi determinada pelo método de difusão em ágar, utilizando a técnica de poço descrita por Silveira (2009) (26) adaptada com os diferentes extratos de C. urucurana utilizando as bactérias Staphylococcus aureus ATCC 25923 e Salmonella typhimurium ATCC 123912. A análise da atividade antioxidante foi realizada pelo método de sequestro do radical livre 2,2-difenil-1-picril-hidrazil (DPPH) descrita por Blois (1958) com adaptações (22).

Material vegetal. As folhas da Croton urucurana foram coletadas na Fazenda Capoeirão, na cidade 
de Inhumas, no Estado de Goiás, no período de janeiro e fevereiro de 2014. Uma amostra do material vegetal foi identificada pelo botânico Esp. José Nogueira e uma exsicata depositada no Herbário da Faculdade Anhanguera de Brasília (FAB) sob o voucher 5.4001. Após a coleta, as folhas foram submetidas a processo de desidratação in natura pelo período de 30 dias, em seguida, secadas em estufa com circulação de ar a $60 \mathrm{C}^{\circ}$ por 60 minutos.

Obtenção dos extratos etanólico, hidroalcoólico e aquoso. Após secagem, o material vegetal foi submetido a trituração com auxílio de um microgranulador oscilante, LEMAQ, com malha ${ }^{\circ} 4$. Foram preparados três extratos: etanólico, hidroalcoólico e aquoso. Foram pesados $40 \mathrm{~g}$ do material vegetal triturado e misturados a $300 \mathrm{~mL}$ de etanol absoluto (99,5\%), em frasco de vidro, para a obtenção do extrato etanólico. Para o extrato aquoso, foram pesados $40 \mathrm{~g}$ de folhas desidratadas e moídas, colocando-as em frasco de vidro contendo 300 $\mathrm{mL}$ de água destilada. Outros $40 \mathrm{~g}$ das folhas desidratadas e moídas da planta foram colocados em frasco de vidro contendo $360 \mathrm{~mL}$ de solução hidroalcoólica (1:1), consistindo em $180 \mathrm{~mL}$ de etanol absoluto $(99,5 \%)$ e $180 \mathrm{~mL}$ de agua destilada, para obtenção do extrato hidroalcoólico. Os três extratos foram submetidos a maceração durante sete dias, com agitação diária, revestindo-se os frascos com papel alumínio, a fim de se proteger o macerado de possíveis alterações por radiação visível. Os frascos ficaram acondicionados em geladeira à temperatura de $2-8{ }^{\circ} \mathrm{C}$ para conservação. Todos os extratos foram filtrados a vácuo e, posteriormente, concentrados no evaporador rotatório. Os três extratos - etanólico, aquoso e hidroalcóolico - foram concentrados a uma temperatura de $60{ }^{\circ} \mathrm{C}$, a $120 \mathrm{rpm}$ no rotaevaporador. Após retirada do solvente foram colocados em estufa a $45^{\circ} \mathrm{C}$ para eliminação total do solvente e formação do extrato seco.

O cálculo do rendimento dos extratos foi realizado dividindo o peso em gramas do extrato pelo peso em gramas da droga vegetal, multiplicando o valor obtido por 100 (23).

Análise fitoquímica qualitativa. Os testes fitoquímicos qualitativos foram realizados por meio de reação química e a presença do composto foi confirmada por precipitação (alcaloide), anel marrom na interface (glicosídeos totais), mudança de coloração (flavonoides, taninos hidrolisáveis e condensados, esteroides, antraquinona e triterpenoides) e formação de espuma (saponinas), conforme a Tabela 1, baseados em Silva, e Cols. (2010) (21), com adaptações.
Tabela 1. Reação positiva na triagem fitoquímica de metabólitos secundários (Silva e Cols, 2010)

\begin{tabular}{|c|c|}
\hline Metabólitos & Reação positiva \\
\hline Alcaloides & $\begin{array}{l}\text { Formação de precipitado insolúvel e } \\
\text { floculoso }\end{array}$ \\
\hline Glicosídeos totais & $\begin{array}{l}\text { Presença de um anel marrom na } \\
\text { interface da mistura }\end{array}$ \\
\hline Antraquinonas & Coloração avermelhada \\
\hline Flavonoides & $\begin{array}{l}\text { Produção de efervescência e } \\
\text { aparecimento de coloração que varia } \\
\text { de parda a vermelha }\end{array}$ \\
\hline $\begin{array}{l}\text { Taninos Hidrolisáveis } \\
\text { e Condensados }\end{array}$ & $\begin{array}{l}\text { A coloração verde resulta em } \\
\text { taninos condensados e formação de } \\
\text { precipitado de coloração azul mostra } \\
\text { a presença de taninos hidrolisáveis }\end{array}$ \\
\hline Esteroides/Triterpenoides & $\begin{array}{l}\text { Presença da coloração azul } \\
\text { evanescente seguida de verde }\end{array}$ \\
\hline Saponinas & $\begin{array}{l}\text { Formação de espuma persistente e } \\
\text { abundante (colarinho }\end{array}$ \\
\hline
\end{tabular}

Atividade antibacteriana. As cepas utilizadas Staphylococcus aureus ATCC 25923 e Salmonella thyphimurium ATCC 14028 - foram diluídas em $10 \mathrm{~mL}$ de solução salina ( $\mathrm{NaCl} 0,9 \%)$ para $5 \mu \mathrm{L}$ de bactéria. $\mathrm{O}$ material foi analisado em espectrofotômetro com comprimento de onda $617 \mathrm{~nm}$ resultando em turvação correspondente a 0,5 da escala McFarland de acordo com Bauer e cols. (1966) (24).

Foram inoculados proporcionalmente $100 \mu \mathrm{L}$ da solução microbiológica no ágar Mueller Hinton e, após secagem de aproximadamente 5 minutos, foram feitos poços de $4 \mathrm{~mm}$, posteriormente acrescentados de $50 \mu \mathrm{L}$ das diluições dos extratos nos poços. A suscetibilidade bacteriana foi avaliada por meio da determinação das concentrações inibitórias mínimas (CIM) de cada extrato, em que se considera a menor concentração capaz de inibir o crescimento de um organismo (25).

As placas foram incubadas em estufa a $36 \pm 1^{\circ} \mathrm{C}$ por 24 horas. $\mathrm{O}$ halo de inibição do crescimento foi medido em milímetros, utilizando paquímetro. Os testes foram realizados em duplicata para maior confiabilidade dos resultados (26). Como controle positivo foi utilizado amoxicilina em disco e como controle negativo água destilada.

Determinação da atividade antioxidante pelo método DPPH. A técnica foi adaptada de Blois (1958) (22), utilizando DPPH (2,2-difenil-1-picril-hidrazil), radical livre estável que possui cor púrpura e é reduzido formando a coloração amarela em presença de antioxidante, podendo a mesma ser monitorada pelo decréscimo da absorbância. A partir dos resultados obtidos foi determinada a atividade antioxidante ou sequestradora de radicais livres (27). 
Para cada extrato foi preparada uma solução-mãe contendo $1000 \mu \mathrm{L}$ de extrato bruto em etanol, e a partir desta, foram feitas diluições sucessivas até a concentração final. No extrato aquoso $(50,100,150,200$, $225,250,275)$; extrato etanólico $(20,25,50,55,75$, 85, 100); hidroalcoólico $(10,20,30,40,50,60,70)$ e, posteriormente, adicionado etanol e tampão acetato 5,5. Como controle positivo, foi realizado um ensaio com ácido ascórbico $\left(\mathrm{C}_{6} \mathrm{H}_{8} \mathrm{O}_{6}\right)$, etanol $95 \%$, tampão acetato de sódio/ácido acético $(0,1 \mathrm{M})$ e 2,2-difenil-1-picrilidrazil (DPPH); para o controle negativo foram utilizados etanol e DPPH. Para cada concentração foi adicionada solução de DPPH $(500 \mu \mathrm{M})$. Quinze minutos após a primeira pipetagem foi feita a leitura no espectrofotômetro em comprimento de onda de $517 \mathrm{~nm}$.

De acordo com Nascimento e cols (2011), a capacidade de eliminar o radical DPPH (\% de atividade antioxidante) foi calculada utilizando a Equação 1 (29).

$$
\% \text { Inibição }=100-\frac{[(\text { Absorbância Amostra }- \text { Absorbância Branco }) \times 100]}{(\text { Absorbância controle })}
$$

Em que:

Absorbância controle = absorbância da solução de DPPH sem a amostra Absorbância amostra = absorbância da amostra com o DPPH.

Absorbância Branco = absorbância de etanol.

$\mathrm{O}$ resultado foi expresso em $\mathrm{CI}_{50}$ (Concentração de Inibição Média), que é a concentração necessária do antioxidante para reduzir $50 \%$ do radical DPPH, sendo que quanto menor o $\mathrm{CI}_{50}$, maior a atividade antioxidante (30). Para o cálculo do $\mathrm{CI}_{50}$ foi utilizada a equação da reta $(y=a x+b)(28)$.

\section{RESULTADOS E DISCUSSÃO}

O rendimento dos extratos secos provenientes das folhas de Croton urucurana Baillon em relação aos diferentes solventes utilizados para extração dos metabólitos foram: extrato hidroalcoólico (17,2\%); extrato etanólico (14\%); extrato aquoso (10\%).

Análise fitoquímica qualitativa. A qualidade das plantas medicinais depende de vários fatores, incluindo variações de espécies, clima, coleta, armazenamento e processamento. A padronização e o controle da qualidade dessas plantas medicinais são importantes para garantir sua eficácia e o uso seguro das mesmas $(27,29)$.

A espécies do gênero Croton (Euphorbiaceae) tem sido atribuidas uma grande variedade de compostos tóxicos e medicinais, tais como compostos fenólicos, incluin- do principalmente flavonoides, lignanas, proantocianidinas, terpenoides, esteroides e alcaloides (30). O teste Shinoda foi positivo para flavonoides em todos os extratos (Tabela 1). Todas as espécies do gênero Croton $(\mathrm{Eu}-$ phorbiaceae) têm apresentado flavonoides, em sua maioria agliconas de flavonois altamente metoxilados (31).

Os flavonoides são um grupo de compostos naturalmente disponíveis, que são uma fonte de interesse para a descoberta de fármacos. $\mathrm{O}$ seu potencial para atuar como agentes anti-tumorigênicos e anti-proliferativos tem sido relatado, além de ter propriedades antiviral, antifúngica, antibacteriana, vasodilatador, anticancerígeno e anti-isquêmico (32-34).

Foram detectadas saponinas no extrato aquoso. Estudos mostram que as saponinas têm um efeito redutor de colesterol no plasma em humanos e são importantes na redução do risco de muitas doenças crónicas. Além disso, mostraram fortes efeitos citotóxicos contra linhas celulares de câncer. No entanto, são necessários mais estudos para a validação adequada dessas atividades de promoção da saúde (35).

O teste para taninos hidrolisáveis foi negativo o extrato hidroalcoólico. Na verificação de presença de glicosídeos totais, os extratod aquoso e etanólico apresentaram resultado positivo.

A composição química de gênero Croton (Euphorbiaceae) pode estar relacionada com vários fatores, entre eles a distribuição geográfica das espécies (36). Este estudo tem mostrado a presença de alcaloides em espécies do velho mundo. Enquanto que em nossos resultados foi verificado a presença de alcaloides na Croton urucurana Baillon, o que mostram confirma a presença deles em espécies das Américas (novo mundo).

A triagem fitoquímica teve como objetivo identificar constituintes químicos presentes nos extratos. A presença de compostos fenólicos, tais como flavonoides e taninos, pode ser correlacionada com o potencial antioxidante que uma espécie vegetal pode apresentar. Os resultados obtidos apresentaram similitude quando comparados com dados descritos por Mattos (37) (Tabela 2).

Atividade antibacteriana. No presente experimento não houve formação de halo de inibição (em mm) dos extratos aquoso, etanólico e hidroalcoólico de Croton urucurana Baillon nas diferentes concentrações testadas $(1: 1,1: 2,1: 4,1: 8,1: 16$ e 1:32) frente ao $S$. aureus e S. typhimurium. A hipótese para esta divergência pode estar nas diferenças de composição que estes compostos podem apresentar devido a fatores climáticos, ambientais e sazonais (38). 
Tabela 2. Análise qualitativa dos compostos fitoquímicos dos extratos de folhas de Croton urucurana.

\begin{tabular}{lcccc} 
& \multicolumn{3}{c}{ Extratos } \\
& Aquoso & Etanólico & hidroetanólico \\
\hline Alcaloides & + & + & + \\
Antraquinonas & - & - & + \\
Esteroides/triterpenoides & - & - & - \\
Flavonoides & + & + & + \\
Glicosídeos totais & + & + & - \\
Saponinas & + & - & - \\
Taninos hidrolisáveis & + & + & - \\
\hline
\end{tabular}

(+) Presença; (-) Ausência.

O estudo sobre o potencial efeito antibacteriano não se inviabiliza pelos resultados mostrados pelos extratos de Croton urucurana Baillon, visto que com outras bactérias mostraram atividade antimicrobiana. Ainda, há variação na sensibilidade para cada tipo de extrato vegetal utilizado, como um estudo de Simmionato e cols. (2007) que mostrou que o óleo essencial bruto de casca de tronco de Croton urucurana Baillon inibiu o crescimento de $S$. epidermidis e E. coli $(\mathrm{MIC}=1,25$ $\mathrm{mg} / \mathrm{mL})(39-41)$.

Determinação da atividade antioxidante pelo método DPPH. As propriedades antioxidantes dos compostos fenólicos têm sido atribuídas à sua capacidade de sequestrar radicais livres gerados na fase aquosa e aumentar a resistência dos lipídeos contra a peroxidação (34). A porcentagem de inibição indica qual é a capacidade das amostras e padrões em sequestrar o radical livre DPPH, sendo que aqueles que produzem um maior percentual de inibição são os mais eficientes (42).

Todos os extratos apresentaram atividade antioxidante, sendo que a mais expressiva foi do extrato hidroalcoólico $\left(\mathrm{CI}_{50}=1,30 \mu \mathrm{g} / \mathrm{mL}\right)$, menor que a do ácido ascórbico $\left(\mathrm{CI}_{50}=2,66 \mu \mathrm{g} / \mathrm{mL}\right)$, utilizado como controle positivo. $\mathrm{O}$ extrato etanólico apresentou o mesmo $\mathrm{IC}_{50}$ do ácido ascórbico. Esta propriedade poderia ser explicada pela presença de flavonoides nos três extratos testados. Lopes e cols (2004) confirmaram a propriedade antioxidante no extrato de Croton lechleri frente a agentes citotóxicos (apomorfina) (43). Os resultados (Figura 2) mostraram que os extratos testados apresentam bom potencial antioxidante quando comparados aos óleos essenciais provenientes da casca do tronco da Croton urucurana Baillon $(44,45)$.

O potencial antioxidante e o teor de compostos fenólicos podem ser úteis para promover outras investigações e correlacionar esta atividade a outras importantes, como por exemplo, à atividade anti-inflamatória. Várias pesquisas sugerem a correlação entre as atividades antioxidante e anti-inflamatória, ou seja, alguns extratos vegetais reduzem inflamações por eliminar superóxidos conhecidos por participarem do recrutamento de células polimorfonucleares (PMN) presentes em tecidos inflamados (44).

Apesar de não ser possível inferir com precisão quais são os compostos responsáveis pela ação antioxidante, os flavonoides devem ser parcialmente responsáveis por esta atividade, tendo em vista os trabalhos que relatam as diferentes atividades exibidas por esta classe de compostos, os quais são descritos preponderantemente como potentes antioxidantes $(42,43)$.

\section{Croton urucurana Baill}

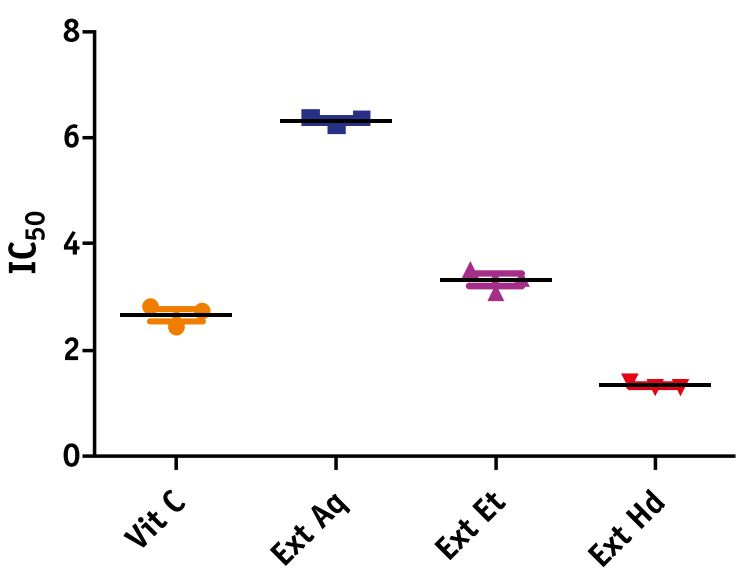

Figura 2. Atividade antioxidante da Croton urucurana Baill. Vit $\mathrm{C}=$ Ácido Ascórbico (Controle); Extrato aquoso (Ext Aq); Extrato Etanólico (Ext Et) e Extrato Hidroalcóolico (Ext Hd). A média mostra os valores do $\mathrm{IC}_{50}$ pela técnica de análise de variância (ANOVA).

\section{CONCLUSÃO}

Todos os extratos apresentaram atividade antioxidante, sendo o extrato hidroalcoólico o que apresentou maior efeito. Na avaliação da atividade antimicrobiana não houve inibição por parte dos extratos.

\section{AGRADECIMENTOS}

Os autores agradecem ao IPADE pela concessão da bolsa de iniciação científica, à Prof ${ }^{a}$ MSc. Danielle Alves de Melo, pelo incentivo e apoio e a todos os funcionários da instituição que de alguma forma, ajudaram na realização da pesquisa. 


\section{REFERÊNCIAS}

1. Perfeito DGA, Corrêa IM, Peixoto N. Elaboração de bebida com extrato hidrossolúvel de soja saborizada com frutos do cerrado. Rev. Agric. Neotrop. 2017; 4(1): 2127.

2. Souza Ferreira RQ, Camargo MO, Teixeira PR, Souza $\mathrm{PB}$, Viana RHO. Uso potencial e síndromes de dispersão das espécies de três áreas de cerrado Sensu stricto, Tocantins. Gl. Sci Tecnol. 2016; 09(3):73-86.

3. Alves MA, Sousa SA, de Souza Silva SC, Souza Nogueira JR, Martins DHN, Fonseca-Bazzo YM, Galdos-Riveros AC. Perfil fitoquímico, capacidade antioxidante e susceptibilidade antibacteriana dos extratos de Morus alba L. (Moraceae). Rev Bras Farm. 2017; 98(1):18111825.

4. Sousa SA, Alves MA, Souza Silva SC, Souza Nogueira JR, Nascimento Martins DH, Fonseca-Bazzo YM, Galdos-Riveros AC. Phytochemical Screening Assessment, Antioxidant Capacity and Antimicrobial Susceptibility of Extracts from Cecropia pachystachya trécul. Cecropiaceae (Urticaceae) As Source for Herbal Medicines Development. Int J Pharmacognosy. 2015; 2(12): 570-576. DOI: 10.13040/ijpsr.0975-8232.ijp.2(12).570-76

5. Ventura PAO, Jesus JPO, Souza Nogueira JR, Galdos-Riveiros AC. Análise fitoquímica e avaliação da susceptibilidade antimicrobiana de diferentes tipos de extratos de Plantago major L. (Plantaginaceae). Infarma. 2016; 28 (1): 33-39. DOI: 10.14450/2318-9312.v28.e1.a2016. pp33-39

6. Rodrigues ML, Souza Nogueira JR, Oliveira BI, Galdos-Riveros AC. Perfil Fitoquímico e Antimicrobiano dos extratos metanólicos e etanólicos da Euphorbia tirucalli L. (Avelóz). Braz. Health Sci. 2015; 1(1): 63-76.

7. Sousa Trindade MJ, Lameira AO. Espécies úteis da família Euphorbiaceae no Brasil. Rev. Cub. Plantas Med. 2014. 19(1): 292-309.

8. Moraes-Souza RQ, Soares TS, Carmo NOL, Damasceno DC, Campos KE, Volpato TV. Adverse effects of Croton urucurana B. exposure during rat pregnancy. J Ethnopharmacol. 2017; 199(4): 328-333 DOI: 10.1016/j. jep.2016.10.061. Epub 2016 Oct 20

9. Antoniazzi CA, Botini N, Ascari K, Chaves CF, Añez RB. Estudo Etnobotânico de Croton urucurana Baill (euphorbiaceae) na comunidade Salobra Grande, Porto Estrela-MT. Biodivers. 2016; 16(2): 40-52.

10. Secco RS et al. An overview of recent taxonomic studies on Euphorbiaceae s.1. in Brazil. Rodriguésia. 2012;63(1): 227-242. DOI: 10.1590/S2175-78602012000100014.

11. Sorreano MCM, Malavolta E, Silva DH, Cabral CP, Rodrigues RR. Deficiência de Micronutrientes em mudas de Sangra d'água (Croton urucurana, Baill.). Cerne, Lavras, 2008;14(2): 126-132. DOI: 10.1590/S010477602011000300008
12. Gurgel LA, Sidrim JJC, Martins DTO, Cechinel V, Rao VS. In vitro antifungal activity of dragon's blood from against dermatophytes. J Ethnopharmacol. 2005; 97(2): 409-412. DOI: http://doi.org/10.1016/j.jep.2004.11.033

13. Simionatto E et al. Bioactivity and Chemical Composition of the Essential Oils of Croton urucurana Baillon (Euphorbiaceae). J. Essent. Oil Bear. Plants. 2009; 12(3): 250-261. DOI: 10.1080/0972060X.2009.10643718

14. Blair JMA, Webber MA, Baylay AJ, Ogbolu DO, Piddock LJV. Molecular mechanisms of antibiotic resistance. Nat. Rev. Microbiol. 2015; 13(1): 42-51. DOI: 10.1038/nrmicro3380

15. Queiroz Santos N. A Resistência Bacteriana no contexto da infecção hospitalar. Texto Contexto Enferm 2004; 13: 64-70. DOI: 10.1590/S0104-07072004000500007

16. Duarte MCT. Atividade antimicrobiana de plantas medicinais e aromáticas utilizadas no Brasil. Rev. MultiCiência. 2006, 7(1): 1-16.

17. Castro Menezes M, Souza MMS, Botelho RP. Avaliação in vitro da atividade antimicrobiana de extratos de plantas Brasileiras sobre bactérias isoladas da cavidade oral de cães. Rev. Univ. Rural. 2004; 24(2):141-144

18. Morais TP, Luz JMQ, Silva SM, Resende RF, Silva AS. Aplicações da cultura de tecidos em plantas medicinais. Rev. Bras. Plantas Med. 2012; 14(1): 110-121 DOI: 10.1590/S1516-05722012000100016

19. Veiga VFJ, Pinto AC, Maciel MAM. Plantas medicinais: cura segura?. Quim. Nova. 2005; 28(3): 519-528 DOI: 0.1590/S0100-40422005000300026

20. BRASIL. Ministério da Saúde. A fitoterapia no SUS e o Programa de Pesquisa de Plantas Medicinais da Central de Medicamentos, Departamento de Assistência Farmacêutica, Brasília: Ministério de Saúde, 2006.

21. Silva NLA, Miranda FAA, Conceição GM. Triagem Fitoquímica de Plantas de Cerrado, da Área de Proteção Ambiental Municipal do Inhamum, Caxias, Maranhão. Sci. Plena. 2010; 6(2): 1-17.

22. Blois MS. Antioxidant determinations by the use of a stable free radical. Rev. Nat. 1958; 181: 1199-1200. DOI: 10.1038/1811199a0

23. Almeida JCS, Rodrigues TS, Souza KF, Rodrigues-DasDores RG, Nagem TJ. Detecção de capsaicina em extratos dos frutos verdes e maduros de Capsicum baccatum L. pelas metodologías de cromatografía em camada delgada e histoquímica. Infarma. 2015; 27(2):106-111. DOI: 10.14450/2318-9312.

24. Bauer AW, Kirby WMM, Sherris JC, Turck M. Antibiotic susceptibility testing by a standardized single disk method. Am J Clin Pathol. 1966; 45(4):493-496.

25. Bona EAM, Silva Pinto FG, Fruet TK, Jorge TCM, Moura AC. Comparação de métodos para avaliação da ati- 
vidade antimicrobiana e determinação da concentração inibitória mínima (CIM) de extratos vegetais aquosos e etanólicos. Arq. Inst. Biol. 2014; 81(3): 218-225. DOI: 10.1590/1808-1657001192012

26. Silveira LMS, Olea RSG, Mesquista JST, Cruz ALN, Mendes JC. Metodologias de atividade antimicrobiana aplicadas a extratos de plantas: comparação entre duas técnicas de ágar difusão. Rev. Bras. Farm. 2009; 90(2): 124-128.

27. Alves CQ, David JM, David JP, Bahia MV, Aguiar RM. Métodos para determinação de atividade antioxidante in vitro em substratos orgânicos. Quím. Nova. 2010; 33(10): 2202-2210. DOI: 10.1590/S0100-40422010001000033

28. Souza CRF, Georgetti SR, Salvador MJ, Fonseca MJVF, Oliveira WPO. Antioxidant activity and physical-chemical properties of spray and spouted bed dried extracts of Bauhinia forficata. Braz. J. Pharm. Sci. 2009; 45(2): 209218. DOI: $10.1590 / \mathrm{S} 1984-82502009000200004$

29. Nascimento JC, Lage LFO, Camargos CRD, Amaral JC, Costa LM, Souza NA, Oliveira FQ. Determinação da atividade antioxidante pelo método DPPH e doseamento de flavonoides totais em extratos de folhas da Bauhinia variegata L. Rev. Bras. Farm. 2011; 92(4): 327-322.

30. Santos KP, Motta LB, Santos DYAC, Salatino MLF, Salatino A, Ferreira MJP, Lago JHG, Ruiz ALTG, Carvalho JE, Furlan CM. Antiproliferative Activity of Flavonoids from Croton sphaerogynus Baill. (Euphorbiaceae). BioMed Res Int. 2015; 212809(1): 1-7. DOI:10.1155/2015/212809.

31. Salatino A, Salatino MLF, Negri G. Traditional uses, chemistry and pharmacology of Croton species (Euphorbiaceae). J. Braz. Chem. Soc. 2007; 18(1):11-33. DOI: 10.1590/s0103-50532007000100002

32. Tawani A, Kumar A. Structural Insight into the interaction of Flavonoids with Human Telomeric Sequence. Sci. Rep. 2015; 5(17574): 1-13. DOI: 10.1038/srep/17574

33. Brodowska KL. Natural flavonoids: classification, potential role, and application of flavonoid analogues. Eur J Biol Res. 2017; 7(2): 108-123. DOI: http://dx.doi. org/10.5281/zenodo. 545778

34. Procházková $\mathrm{D}$, Bousová $\mathrm{B}$, Wilhelmová. Antioxidant and prooxidant properties of flavonoids. Fitoterapia. 2011; 82(4): 513-523. DOI: 10.1016/j.fitote.2011.01.018

35. Singh B, Singh JP, Singh N, Kauar A. Saponins in pulse and their health promoting activies: A review. Food Chem. 2017; 233:540-549. DOI: 10.1016/j.foodchem.2017.04.161.
36. Turiel NA, Ribeiro AF, Carvalho EEN, Domingos VD, Lucas FCA, Carreira LMM, Andrade EHA, Maia JGS. Essential Oils Composition of Croton Species from the Amazon. Nat. Prod. Commun. 2013; 8(10): 1471-1472.

37. Matos LMM. Química de espécies nativas de Croton L. (Euphorbiaceae). [Tese]. São Paulo: Universidade de São Paulo. 2011

38. Carvalho AF, Silva DM, Silva TRC, Scarcelli E, Manhani MR. Avaliação da atividade antibacteriana de extratos etanólico e de ciclohexano a partir das flores de camomila (Matricaria chamomilla L.). Rev. Bras. Plantas Med. 2014;16(3): 521-526. DOI: 10.1590/1983-084X/12_159.

39. Simionatto E, Bonani VFL, Morel AF, Poppi NR, Raposo-Júnior JL, Stuker CZ, Peruzzo GM, Peres MTLP, Hess SC. Chemical composition and evaluation of antibacterial and antioxidant activities of the essential oil of Croton urucurana Baillon (Euphorbiaceae) stem bark. J Braz Chem Soc. 2007; 18(5), 879-885, DOI: 10.1590/ S0103-50532007000500002

40. Obey JK, Wright V, Orjala J, Kauhanen J, Tikkanen-Kaukanen C. Antimicrobial Activity of Croton macrostachyus Stem Bark Extracts against Several Human Pathogenic Bacteria. J Pathog. 2016; 1453428(1): 1-5. DOI:10.1155/2016/1453428

41. Peres MTLP, Monache FD, Cruz AB, Pizzolatti MG, Yunes RA. Chemical composition and antimicrobial activity of Croton urucurana Baillon (Euphorbiaceae). J Ethnopharmacol. 1997; 56(3): 223-226. DOI: 10.1016/ S0378-8741(97)00039-1

42. Rosa EA, Silva BC, Silva FM, Tanaka CMA, Peralta RM, Oliveira CMA, Ferreira HD, Silva CC. Flavonoide e atividade antioxidante em Palicourea rígida Kunth Rubiaceae. Rev. Bras. Farmacogn. 2010; 20(4):484-488. DOI: $10.1590 / \mathrm{S} 0102-695 X 2010000400004$

43. Lopes MIL, Saffi J, Echeverrigaray S, Henriques JAP, Salvador M. Mutagenic and antioxidant activities of Croton lechleri sap in biological systems. J Ethnopharmacol. 2004; 95(2-3): 437-445. DOI: 10.1016/j.jep.2004.08.025

44. Brito, MS. Prospecção química e avaliação da atividade antioxidante de extratos dos caules de Croton linearifolius (Euphorbiaceae). [Dissertação]. Itapetinga: Universidade Estadual do Sudoeste da Bahia, Bahia. 2014

45. Peres MTLP, Monache FD, Cruz AB, Pizzolatti MG, Yunes RA. Chemical composition and antimicrobial activity of Croton urucurana Baillon (Euphorbiaceae). J Ethnopharmacol. 1997; 56(3): 223-226. DOI: 10.1016/ S0378-8741(97)00039-1 